\title{
A literatura e o cinema como novo medium artístico: Hanns Heinz Ewers e O estudante de Praga (1913)
}

\author{
Michael Korfmann* \\ Filipe Kegles Kepler**
}

\begin{abstract}
The Student from Prague (1913) is considered to be the first film d'art produced in Germany. The film is based on a script by Hanns Heinz Ewers, writer and ardent advocate of this new medium. With roots in German romanticism, particularly in regard to motifs in the works by E.T.A. Hoffmann and Adelbert von Chamisso, The Student from Prague explored the optical possibilities offered by the doppelganger character. This literary framework supports the plot, gives credibility to the movie and contributes to the acceptance of films as an art medium. It also marks the rise of German cinema on an international level, which reached its peak in the 1920s with the movement known as 'German expressionism'.
\end{abstract}

Keywords: The Student from Prague; Hanns Heinz Ewers; German cinema.

Resumo: O estudante de Praga (1913) é considerado o primeiro filme de arte produzido na Alemanha. Baseado num roteiro de Hanns Heinz Ewers, escritor e defensor destacado do novo medium fílmico, o filme remonta a motivos da tradição literária do romantismo alemão, sobretudo em relação às obras de E.T.A. Hoffmann e Adelbert von Chamisso e à figura do doppelgänger. Todo esse arcabouço literário não só dava sustentação à trama como também credibilidade ao filme, contribuindo, junto com a exploração dos recursos técnicos de câmera, para a aceitação definitiva do filme como medium de arte, bem como para o início do sucesso do cinema alemão, que atingiria seu apogeu nos anos 1920, com o movimento conhecido como "expressionismo alemão".

Palavras-chave: O estudante de Praga; Hanns Heinz Ewers; cinema alemão.

Stichwörter: Der Student von Prag; Hanns Heinz Ewers; Deutscher Film.

\section{Introdução}

O estudante de Praga (1913) de Stellan Rye e Hanns Heinz Ewers figura na história do cinema alemão como o primeiro filme de arte produzido no país. Aliando inovações técnicas a um enredo consistente, desenvolvido especialmente de modo a explorar as possibilidades técnicas do cinema, o filme foi aclamado pelo público e pela crítica, sendo considerado, segundo o crítico David RoBINSON, como "the one really singular pre-war German production, which succeeded in attracting intellectuals and

\footnotetext{
* Professor do Departamento de Línguas Modernas da UFRGS. E-mail: michael.korfmann@ufrgs.br

** Bolsista do CNPq. E-mail: filipe.kepler@gmail.com
} 
popular audience alike” (ROBINSON 1973: 88). O filme narra a história do solitário estudante Balduin, que, ingênuo e ébrio de amor pela condessa Margit, assina um acordo com o misterioso Scapinelli no qual consente que, em troca de cem mil moedas de ouro, este tenha total liberdade para levar consigo o que quiser de seu quarto. Scapinelli, então, mediante magia, "liberta" o reflexo de Balduin do espelho, transformando-o num doppelgänger, que passa a assombrar e a perseguir o estudante. $\mathrm{O}$ roteiro ficou a cargo do escritor Hanns Heinz Ewers, personalidade excêntrica e polêmica, que naquela época encontrava-se no auge de sua fama; a direção é do dinamarquês Stellan Rye, um dos diretores mais influentes na Alemanha pré-Primeira Guerra, que lamentavelmente viria a morrer logo no ano seguinte, em 1914, num hospital militar francês; o papel principal do estudante Balduin e seu doppelgänger foram representados pelo conhecido ator de teatro Paul Wegener, que a partir de então atuou ativamente no cenário cinematográfico alemão, trabalhando como ator, diretor e roteirista.

Traçamos, assim, as linhas gerais a serem exploradas neste artigo: primeiro, a figura de Hanns Heinz Ewers, um dos escritores mais famosos da Alemanha do início do século XX e um dos poucos a apoiar incondicionalmente o cinema como novo medium artístico. Segundo, o surgimento do novo medium filme e a disputa inicial entre este e a literatura como forma artística tradicional e consolidada; como terceira linha, aborda-se o fato de o cinema alemão recorrer a matéria, personagens e motivos do romantismo, o que se dava por dois motivos básicos: o romantismo era um movimento reconhecido mundialmente e, portanto, ideal para atribuir ao filme o status artístico, uma vez que o novo medium era ainda considerado por muitos como uma forma plebéica de entretenimento. Paralelamente, o romantismo oferecia um vasto campo narrativo que ia ao encontro das novas possibilidades técnicas do cinema, seja com o já citado doppelgänger romântico, possibilitando truques óticos através da técnica do stop trick (ou “dupla suposição”), desenvolvidas nas cenas mágicas de Méliès, seja com as encenações na tradição fantasmagórica da lanterna mágica. Sintomático é o fato de que, no início e no fim da produção do período do cinema "mudo"1 alemão mais narrativo e elaborado, encontrem-se O estudante de Praga (1913), inspirado, entre outros, por E.T.A. Hoffmann e Adelbert von Chamisso, e o Faust (1926) de Murnau.

\footnotetext{
${ }^{1}$ Sabe-se que os filmes raramente eram apresentados sem acompanhamento sonoro, quer de músicas mecânicas, orquestra, diversas máquinas (por exemplo, máquinas de sons como o Bruitophone,
} 


\section{Hanns Heinz Ewers}

Iniciemos nossa abordagem com algumas considerações sobre Ewers (18711943). Como muitos outros autores de língua alemã (entre eles Goethe, Novalis, os irmãos Grimm, Heinrich Heine ou Franz Kafka), Ewers estudou Direito, mas logo passou a dedicar-se exclusivamente à atividade de escritor. Após os primeiros sucessos, no início do século XX, colaborou com o Überbrettl - o primeiro cabaré literário de Berlim, fundado em 1901 por Ernst von Wolzogen nos moldes do chat noir parisiense, e, por um breve período, também o local de trabalho de Arnold Schönberg, mais tarde conhecido por suas composições dodecafônicas ou expressionistas. No mesmo período atuava lá também Rideamus, pseudônimo de Fritz Oliven, um dos mais conhecidos humoristas alemães e também libretista de operetas de sucesso, que, em 1939, exilou-se em Porto Alegre, onde veio a falecer em $1956 .{ }^{2}$ Ewers, admirador de Oscar Wilde e Edgar Allan Poe, escreveu muito e depressa: poesia, drama, versos para os cabarés, libretos, contos, romances, tratados científicos populares (por exemplo, sobre formigas), bem como relatos de experiências próprias com drogas como haxixe e mescalina, ou ainda impressões de diversas viagens pelo mundo, entre as quais, uma excursão realizada ao Brasil, Argentina e Paraguai, por volta de 1908. Tornou-se conhecido do grande público tanto por seus textos de horror e elementos fantásticos, com doses elevadas de perversidade, como por sua auto-encenação de dandy e boêmio par excellence. Seu romance Alraune (1911) recebeu, em apenas dois anos, 25 edições, foi traduzido para 28 línguas e filmado quatro vezes. Após um certo declínio profissional e pessoal nos anos 20, aproximou-se de círculos da extrema direita. Encontrou-se com o futuro ministro de propaganda do Terceiro Reich, Joseph Goebbels, e, supostamente, filiou-se ao partido nacional-socialista em 1931, num encontro pessoal com Hitler, que lhe encomendaria um livro sobre a luta entre a SA e os comunistas: o romance Horst Wessel, publicado em 1932. No ano seguinte, a matéria já virava filme, sob a direção do próprio Ewers, porém Goebbels logo proibiria sua distribuição, alegando "falhas artísticas”. Em seguida, também o regime viria a proibir quase toda a venda da produção

Noiseograph, Soundograph , Dramagraph, Excellsior Sounds Effects Cabinet e Deagan Electric Bells), quer de atores declamando e cantando em voz alta os "diálogos" ou cenas musicais atrás da tela. ${ }^{2}$ ver: KORFMANN, Michael. RIDEAMUS in Brasilien: Ein nicht ganz so heiteres Leben. In: TÓPICOS 4/2002-1/2003, p. 40-41. 
literária de Ewers, considerada decadente e doentia. O autor morreu em 1943, em Berlim. $^{3}$

Evidentemente, esta aproximação de Ewers com os nacional-socialistas paira sobre qualquer avaliação de sua literatura e seu papel como defensor do cinema em sua fase inicial. Porém, o mesmo mal-estar vale para vários outros autores alemães inicialmente fascinados pela nova força política, como Gerhart Hauptmann ou Gottfried Benn. Ao enfatizarmos, nas próximas páginas, o papel central que Ewers desempenhou na configuração do cinema alemão, não visamos a qualquer revisionismo político ou tentativa de ocultar este período de sua biografia, mas apenas destacar seu posicionamento durante a implementação cultural do novo medium fílmico.

\section{O cinema e a literatura}

De uma maneira geral, pode-se dividir o desenvolvimento do filme "mudo" em três etapas: a primeira pode ser considerada um espetáculo técnico, o prazer de ver quaisquer imagens em movimento dentro de apresentações diversas em variétés ou feiras populares. Na segunda fase, estabelecem-se lugares fixos para as sessões cinematográficas, primeiras formas básicas de genre e padrões de expressão fílmica, bem como uma disputa entre indústrias cinematográficas de diversas nações. Por fim, na terceira etapa, através do refinamento dramatúrgico, da inserção de atores e diretores teatrais e a aproximação com a literatura, o cinema se consolida como medium artístico, inclusive a assimilação do criador genial, seja ele roteirista, diretor ou ator/atriz elementos até então desconhecidos dos curtos filmes projetados. Em 1900, os filmes “documentários”, ou melhor, as cenas do cotidiano, representavam ainda 87\% da produção total, enquanto já em 1908, em decorrência da criação de salas específicas de projeção e de condições cinematográficas mais estruturadas, esta relação se invertia: 96\% dos filmes eram de caráter ficcional e apenas 4\% de caráter documental. Vale lembrar que neste contexto não foram mostradas somente as já bem conhecidas cenas do cotidiano ou episódios humorísticos, mas houve também uma utilização intensiva do filme na área científica, sobretudo na medicina, onde logo se reconheceu o valor didático da nova invenção. A revista Der Kinematograph já descreve, na sua segunda edição, a aplicação do filme para a "representação do corpo doente e os métodos de

\footnotetext{
${ }^{3}$ Informações básicas online, oferecidas pela Sociedade Hanns Heinz Ewers: http://www.hanns-heinz-
} 
intervenções medicinais” (Der Kinematograph 1907: s.p.). Cenas de epilepsia, operações e amputações são logo exploradas sob perspectiva fílmica Já em 1898, o médico Eugène-Louis Doyen mostrava em um congresso em Edimburgo suas intervenções, filmadas por Clément Maurice, um ex-cameraman da empresa Lumière. Tais filmes também serviam depois como atrações mórbidas em mostras de feiras populares e salas improvisadas de projeção, contribuindo, assim, para a má fama inicial do cinema.

Com o desenvolvimento de filmes mais extensos, desenvolveu-se também uma linguagem cinematográfica mais narrativo-ficcional, apoiada sobretudo em figuras e estruturas literárias. Sintomático aqui é o fato de que havia, já nos primeiros anos da história cinematográfica, aproximadamente 70 cenas baseadas na figura do Fausto, seja por tratar-se de uma personagem conhecida, evocando, assim, a curiosidade do público; seja por tal motivo permitir a exploração de efeitos visuais não realizáveis em palcos de teatro, o que mostraria, no tocante à visualidade, a superioridade do medium fílmico em relação às demais formas artísticas existentes. Certos críticos da época, como Béla BALÁzs, viam na “mudez" e na concentração no elemento ótico uma volta ao comportamento original humano, supostamente dominado pelo gesto: “toda humanidade está hoje em processo de reaprender a linguagem esquecida de gestos e mímica”, uma vez que não é a palavra mas a "correspondência visual que representa a alma” (BALÁzs 1962: 60). Em contrapartida, Jurij M. LOTMANN destaca a palavra como elemento indispensável, cuja falta devia ser superada no filme mudo: “A palavra não é uma característica facultativa e suplementar da narrativa fílmica, mas elemento obrigatório. Filmes mudos sem letreiros ou filmes sem diálogos apenas confirmam isso, pois o espectador nota permanentemente a falta do texto falado; nestes casos, a língua funciona como meio artístico negativo” (LOTMANN 1977: 60).

Independentemente de concordarmos ou não com tais afirmações, é seguro afirmar que o filme começa a se diferenciar e, conseqüentemente, a se configurar através de meios próprios: posicionamento e ângulo da câmera, corte, montagem e, na tentativa de visualizar a fala, recorre-se a imagens típicas da boca em movimento e, até, ao grito silencioso. Sobretudo os letreiros, inseridos basicamente a partir de 1907, introduziram a referência escrita e freqüentemente literária, que, por sua vez, foi combatida rigorosamente pelo movimento vanguardista dos anos 20 como sendo um 
elemento anti-fílmico. Hans Werner Richter declara em 1925: “ainda não existem filmes, apenas uma forma perversa de literatura fotografada” (apud SCHOBERT 1989: 9); e RUTTMANN exclama: “a literatura não tem nada a ver com o cinema, pois o significado de qualquer espetáculo cinematográfico nos é transmitido através da vista e, portanto, apenas pode tornar-se uma experiência artística se for concebido de maneira ótica” (apud SCHOBERT 1989: 8).

Voltemos ao nosso ponto central, $O$ estudante de Praga e a luta inicial do filme com pretensões artísticas de inserir-se no cenário cultural alemão da época. O filme surge numa época em que o cinema experimentava uma crise: nos anos de 1907-08, em virtude de uma superprodução de filmes, o interesse pelo cinema aos poucos arrefecia, uma vez que "o público mostrava-se cada vez mais enfastiado com os simplíssimos roteiros dos melodramas feitos às pressas e das repetitivas perseguições 'cômicas' que dominavam a tela” (DiEDERICHS 1985: 5). De modo a reverter a situação e renovar o interesse do público pelo novo medium, Pathé Frères funda, na França, a "Société cinématographique des auteurs et des gens de lettres” (S.C.A.G.L.), que visava a elevar o nível dos filmes da época. Para tanto, reuniam-se escritores e teatrólogos renomados para adaptações cinematográficas de peças célebres, bem como para a produção de roteiros originais. Além disso, contava-se também com a participação de atores famosos de teatro, a fim de atrair o público e trazer mais prestígio às produções.

No outono de 1908 há uma tentativa por parte do diretor e escritor Heinrich Bolten-Baecker de se criar uma sociedade semelhante na Alemanha. Ele reúne cento e vinte romancistas e dramaturgos berlinenses para uma assembléia, na qual discorre sobre as grandes possibilidades artísticas e financeiras dos escritores no cinema. Apesar do grande interesse demonstrado pelos participantes, a iniciativa acaba em fracasso. Conforme atesta Helmut DiEDERICHS, “apenas quatro anos mais tarde o modelo dos filmes de arte franceses encontraria seus imitadores na Alemanha” (DIEDERICHS 1985: $6)$.

A partir de 1913 surgem os chamados “filmes de autor”, dentre os quais estaria O estudante de Praga. A proposta desses filmes era primeiramente a de reavivar o interesse do público pelo cinema, mas, ao mesmo tempo, de estabelecer junto à crítica a legitimação cultural do filme como mídia respeitável. Pois, à medida que surgiam mais salas de exibição e aperfeiçoavam-se as técnicas de projeção e filmagem, o cinema ia deixando de ser uma mera curiosidade técnica de feiras populares para tornar-se um verdadeiro “concorrente da literatura reinante” (KAES 1978: 2). Essa progressiva 
ascensão da nova mídia chocava-se, na Europa, com a resistência de uma elite burguesa que, educada tradicionalmente no teatro e na literatura, ainda via no cinema uma forma de contracultura que buscava equiparar-se à cultura oficial. "Raramente, na área artística e cultural, travou-se uma luta tão feroz como a atual sobre o valor ou não-valor do cinema”, escrevia o crítico TANnENBAum, em 1913 (TANNENBAum 1913: 60).

Thomas MANN, representante máximo da cultura do livro, talvez seja quem melhor sintetize o posicionamento público daqueles que, na melhor das hipóteses, viam o filme como uma mera forma de entretenimento. Ele escreve: "visito cinemas freqüentemente e não me canso de assistir a esta diversão visual e musicalizada” ou “aos jornais vivos chamados reportagens semanais (Wochenschau)”. Também se diverte com “as cenas cômicas, as malandrices ou as histórias sentimentais”. "Porém”, continua MANN,

permitam-me dizer, o filme não tem nada a ver com a arte e acho errado abordá-lo com critérios emprestados da esfera artística. Esta é uma abordagem feita por mentes humanistas e conservadoras que depois viram as costas, cheios de desprezo e lamento, considerando-o uma diversão baixa e selvagemente democrática das massas. No que diz respeito a mim, também desprezo o cinema, mas também o amo. Não é arte, antes vida e realidade, e os efeitos em sua mudez movimentada são sensacionalmente rudes em comparação com os efeitos espirituais da arte”. Conforme Mann, o filme vive de primeira mão, objetivando impressionar o espectador com matéria direta, não refletida, enquanto a arte "é uma esfera fria, (...) um mundo da espiritualização e elevada transposição, um mundo do estilo, da assinatura, da formatação mais individual, mundo objetivo e mundo racional (apud KAES 1978: 164-165). ${ }^{4}$

É possível que a decepção com a versão cinematográfica de 1923 de seu romance Buddenbrooks (1901) tenha contribuído para esta avaliação de Mann, escrita em 1928 e, portanto, na fase em que o cinema, sobretudo o cinema alemão, já se consolidara com produções prestigiosas como O Gabinete do Dr. Caligari (1920) de Robert Wiene, Nosferatu (1922) e Fausto (1926) de Murnau, ou Metropolis (1927) de Fritz Lang. Parece que Mann se serviu da mesma condenação ao cinema em seu então work in progress, o romance A Montanha Mágica (1924), no qual Hans Castorp deixase convencer a acompanhar uma paciente do sanatório, a Senhora Stöhr, a uma sessão do Bioskop-Theater, a fim de lá assistir "uma dose de vida cortada em pedacinhos”; e esta "apresentação inumana” deixa-lhe os "olhos doloridos”.

\footnotetext{
${ }^{4}$ Esta e todas as citações de fontes em língua alemã foram traduzidas por Filipe K. Kepler.
} 
Todavia, como mostra Peter ZANDER, em seu livro Thomas Mann no cinema (2005), a relação de Mann com o cinema era, no mínimo, ambígua. Não apenas apoiou inicialmente a filmagem do romance Buddenbrooks, como também esboçou, em 1923, um script para uma versão cinematográfica de Tristan und Isolde e, posteriormente, trabalhou em mais dois roteiros, todos não concluídos. Ao contrário de suas reclamações sobre a crueza do cinema no artigo citado acima, foram justamente estes filmes artisticamente menos pretensiosos que caíram nas graças do escritor: em seus diários, elogia Jungle Book (1942, baseado no livro de Rudyard Kipling e dirigido por Zoltán Korda) pelas belas imagens dos animais e pelos belos corpos apresentados; também assistiu duas vezes ao desenho animado Bambi. Portanto, é necessário diferenciarmos aqui entre as manifestações públicas e as anotações particulares de Thomas Mann. E é justamente em relação à discussão pública que surge a figura de Hanns Heinz Ewers; este se destaca nas polêmicas iniciais sobre o status artístico ou não do novo medium fílmico. Já em 1907, o autor, conhecido na época por seus textos grotescos e fantásticos e por sua vida boêmia, publica sua primeira declaração favorável ao cinema na revista semanal Morgen, editada, entre outros, por Hugo von Hofmannsthal. "Será possível que os jornalistas sejam cegos? Não sabem eles que o cinema é um fator cultural tão importante e de um impacto tão grande como nenhum outro? Que pode ser colocado ao lado da invenção de Gutenberg, à qual nós, escritores, devemos a vida?” (EWERS 1907: s.p.). Em 1910, conseguiu inserir uma rubrica permanente na revista Deutsche Montags Zeitung sobre assuntos ligados ao cinema, como censura, cinema e teatro ou cinema e ciência. EWERS usa esta rubrica para atacar a censura e o baixo nível das produções alemãs, às quais, segundo ele, faltava coragem para a experimentação, uma vez que tais filmes preocupavam-se tão-somente em agradar à censura e ao gosto duvidoso do público. O autor realizou palestras sobre o “milagre do filme em rolo”, apontando não apenas para seu uso nas ciências, na indústria e também como meio de propaganda comercial, mas já prevendo também o futuro filme sonoro e as possibilidades de divulgar peças teatrais registradas em filme para um público sem acesso a tais estabelecimentos. Criticou a moda das "imagens sonoras” onde "são mostradas cenas de mau gosto de óperas e operetas acompanhadas por um som repugnante de fonógrafo” (EWERS 1911: s.p.).

Não havia, neste momento, uma inclusão de escritores conhecidos na produção cinematográfica na Alemanha. Impulsionados pela insistência de Ewers e de outras pessoas pertencentes a um grupo chamado reformistas do cinema - que objetivava 
produzir filmes de nível mais elevado e tinha em vista a burguesia como novo públicoalvo -, diversas empresas, entre elas a Deutsche Bioscop-Gesellschaft ou o Nordische Films Co., anunciavam a integração de escritores renomados em suas equipes, como Ewers, Max Halbe ou Gerhart Hauptmann. Havia, naturalmente, manifestações contrárias a esta união. O poeta Hans Kyser proclama que "o poeta não deve ir ao cinema”, baseando sua posição na falta insuperável da palavra nos filmes, e não hesita mesmo em citar a Bíblia: "Deus falou e assim criou-se o mundo/No início era a palavra”. EWERS responde citando o Fausto de Goethe: “Escrito está: 'Era no início a palavra!'. Apenas começo e já me exacerbo! Como hei de dar à palavra tão alto apreço? De outra interpretação careço” (EWERS 1913a: s.p.). E é na própria figura de Kyser que também se revela o processo da consolidação do filme como forma artística e cultural: após a posição crítica inicial, Kyser aproxima-se gradualmente do novo medium. A partir dos anos 1920, ele passa a transformar fontes literárias em cenários para o cinema. O adversário de Ewers e, por conseguinte, do filme $O$ estudante de Praga como "marco zero” da produção de ambições artísticas, torna-se mais tarde o autor do script para o Faust de Murnau (1926), considerado por muitos o auge do cinema mudo alemão. Em 1927, arrisca-se até a dirigir um filme, porém, não passa de uma incursão única; fora isso, continua escrevendo roteiros até meados dos anos 1930, entre eles, ironicamente, um remake de 1935 do próprio Estudante de Praga, com direção de Arthur Robinson.

Ewers logo transforma seu engajamento teórico em práxis fílmica. Inicia com colaborações no cenário de $O$ seduzido (1913), onde trabalha pela primeira vez com o autor Paul Wegener. Porém, ambos ficam tão descontentes com o resultado que a película é afinal destruída. Entretanto, tudo isso muda com $O$ estudante de Praga. A idéia central do filme, o motivo do doppelgänger, partiu primeiramente de Wegener e foi então desenvolvida por Ewers em um script mais extenso. Ele mesmo comenta: “escrevi uma peça para um filme de rolo: O estudante de Praga era seu título. Escrevi-a para Paul Wegener e trabalhei com este durante meses na sua versão final, em Praga e aqui, em Berlim. Era para ser uma prova, era para provar para mim que o cinema, assim como o teatro, pode hospedar grande e boa arte” (EwERS 1913b: s.p.). E filmes de arte não precisam apenas elaborar uma narrativa consistente; esta precisa também ser encenada de acordo com as possibilidades mediais. A respeito desta relação entre texto e filme, Rudolf KURTz declara: "O manuscrito se configurou em direção às possibilidades desta arte. Procuravam-se imagens. Procuravam-se criar efeitos de iluminação. Havia um grande esforço no intuito de congregar atmosferas. O manuscrito 
puramente técnico do filme ganhou sem dúvida um ímpeto poético” (KURTZ 1934: s.p.). Todos estes itens ainda podiam contar com uma certa familiaridade do público em relação às referências dos elementos fantástico-românticos do filme: "O estudante de Praga abriu para o espectador alemão a porta para o mundo da fantasia, ele tocou as predisposições já existentes no público, uma preferência por uma literatura de atmosfera irreal, adquirida na educação familiar e escolar” (TOEPLITZ 1972: 135).

\section{O estudante de Praga}

Em 22 de agosto de 1913, estreava, em Berlim, O estudante de Praga, com o qual teria início, “também na Alemanha, a história dos filmes artisticamente ambiciosos” (PAECH 1988, p. 103). Como praxe bastante comum, O estudante de Praga viria a ser refilmado mais duas vezes: em 1926, por Henrik Galeen, e, em 1935, como produção sonora por Arthur Robinson. Mas limitemo-nos aqui à versão inicial. O filme remonta à tradição literária do romantismo, com seus heróis desesperados, a reverência à natureza e a presença sinistra do sobrenatural. Os motivos literários presentes no roteiro dialogam claramente com a obra de E.T.A. Hoffmann, em criações como Die Doppelgänger (1812), Die Geschichte des verlornen Spiegelbildes (1815), Der goldene Topf (1814), bem como com o romance Peter Schlemihls wundersame Geschichte (1813), de Adelbert von Chamisso. Ambos os autores foram reconhecidos e apontados por quase toda a crítica como os principais modelos literários do filme; Chamisso, em particular, era citado com freqüência nos jornais da época: falava-se em "balada de Schlemihl” (Volkszeitung), “variante de Schlemihl” (Vossische Zeitung) e “contrapartida de Peter Schlemihl” (Berliner Lokalanzeiger, apud DIEDERICHS 1985: 26). A referência literária era apontada também no jornal Tägliche Rundschau de 23 de agosto de 1913: "seus padrinhos ilustres são Goethe, Chamisso, Amadeus Hoffmann e Oscar Wilde (...) Seu sangue corre, de modo bastante elegante e assombroso, nas veias deste drama fantástico” (apud PRINZLER 1986: 262).

Além da influência romântica, o filme remonta igualmente ao universo da lenda e da cultura popular. O trágico desenlace da história do estudante Balduin, assombrado por sua cópia fantasma, não coincide com o destino das personagens de Erasmus Spikher (Die Geschichte des verlornen Spiegelbildes) e Peter Schlemihl, pois, enquanto estas ainda conseguem ao final "libertar-se do mal” (JöRG 1994: 89), em O estudante de 
Praga, a história termina com a morte do herói e o triunfo da aparição. O teor pessimista de tal desfecho coaduna-se com as histórias de doppelgänger presentes na prosa popular, segundo as quais “a visão de um doppelgänger geralmente anunciava a morte da respectiva pessoa” (JÖRG 1994: 103). Da mesma forma, a libertação e o roubo do reflexo de Balduin estão diretamente ligados à crença popular de que a alma humana encontraria na sombra, numa visão e no reflexo do espelho "um substituto do corpo" (MENGIS 1987: 348).

Todo esse arcabouço folclórico-literário não só dava sustentação à trama, como também credibilidade ao filme, contribuindo significativamente para sua aceitação. Graças ao sucesso e reconhecimento de $O$ estudante de Praga, muitos filmes nos próximos anos haveriam de seguir-lhe a proposta "literária”. Pois, conforme postula Anton KAES, “através de sua hábil acomodação à literatura da época, o cinema conseguia gradualmente superar o estigma de sua origem plebéia e convencer a burguesia - necessária para a ampliação da base de recepção - de seu potencial artístico” (KAES 1978: 2).

Além de representar a estréia no cinema alemão de um roteiro escrito exclusivamente para um filme, $O$ estudante de Praga causou sensação também pela inovação no tocante à música. Ao contrário da prática comum da época de se utilizarem trechos musicais como música de fundo, o projeto de Rye contou com a participação do célebre compositor húngaro Josef Weiss, que não só compôs um acompanhamento musical especialmente para o filme, como o tocou ao piano na sua première, em Berlim. Lia-se no jornal berlinense Tägliche Rundschau do dia 2 de setembro de 1913: "Sem excessivas surpresas sonoras e sensacionalismos, baseando-se em danças e melodias folclóricas eslavas - também Chopin emerge visivelmente na singular 'polonaise' -, o compositor dá às imagens um abaulamento musical sumamente agradável” (apud DIEDERICHS 1985: 23).

Stellan Rye foi muito elogiado também pela fotografia do filme, na qual se exploraram as nuanças dos efeitos de luz; admiravam-se as cenas de "maravilhoso efeito pictórico” (Zeit am Montag, apud DiEDERICHS 1985: 26). A referência da crítica à pintura se deveu em especial ao tipo de iluminação inaugurada no filme, que lembrava os quadros de Rembrandt. Este explorava em suas obras os diferentes matizes obtidos pelo contraste entre luz e sombra: os objetos não se apresentavam na sua cor própria, mas assumiam antes o tom ditado pela incidência de luz, o que resultava num forte contraste entre áreas claras e escuras. Em O estudante de Praga, utiliza-se uma técnica 
similar de iluminação: em vez de se iluminarem igualmente a frente e o fundo da imagem, como era de praxe nos filmes da época, o fundo permanece escuro, enquanto os atores são iluminados parcialmente; as personagens se destacam, enquanto os cenários deixam-se entrever apenas por contornos - esse jogo de luz e sombra conferia às cenas um clima duvidoso, ambíguo. Criava-se, assim, um mundo de sombras e, dentro da proposta do filme, um ambiente de mistério e horror. Esse estilo de iluminação, que seria adotado em muitos filmes posteriores, vindo a transformar-se na marca registrada do cinema alemão, ficou popularmente conhecido como german lighting.

Aliadas à iluminação, contribuíram também para a atmosfera poéticofantasmagórica da trama as cenas das ruas e da natureza de Praga. As belas tomadas externas, filmadas na parte histórica da cidade, não passaram despercebidas aos olhos da crítica, que louvou “a beleza imortal da falecida Praga” (PRINZLER 1986: 262), bem como os efeitos obtidos ao ar livre: "representava-se o vento; podíamos reconhecê-lo em árvores balançando ou então nos cabelos de Wegener” (apud JöRG 1994: 74).

Não obstante todas as inovações acima descritas representarem uma grande realização no quadro da cinematografia alemã da época e terem, de fato, contribuído para a boa recepção do filme, o motivo principal do estrondoso sucesso de $O$ estudante de Praga foram realmente as cenas com o doppelgänger. Sua realização na tela, a possibilidade de Paul Wegener contracenar com Paul Wegener - com seu próprio reflexo animado -, arrebatou o público e arrancou da crítica elogios dos mais entusiásticos. "O filme conseguiu os atrativos mais intensos a partir do horror de uma figura de doppelgänger real, fantasmagórica, impossível no teatro, e de sua enigmática criação técnica” (Neues Tagblatt für Stuttgart, apud DiEDERICHS 1985: 25).

Todavia, o truque de câmera por meio do qual Guido Seeber dera vida à cópia fantasma do estudante Balduin não era de todo inédito. Tratava-se do stop trick, descoberto acidentalmente, em 1896, pelo francês George Méliès, considerado o pai da arte cinematográfica. Certa vez, enquanto Méliès filmava um objeto em movimento, sua câmera emperrou por alguns segundos, porém logo voltou a funcionar. Ao rever o filme, ele percebeu que, nos frames em que a câmera deixara de rodar, o objeto tinha desaparecido. Méliès utilizaria essa técnica em seus filmes para realizar truques de mágica, como, por exemplo, fazer uma garota desaparecer e, após um gesto seu, reaparecer em seguida. Em O estudante de Praga, as cenas do doppelgänger eram filmadas de maneira semelhante. O momento, por exemplo, de sua primeira aparição - 
quando Balduin vê diante dos próprios olhos seu reflexo libertar-se do espelho e vir ao seu encontro - dava-se da seguinte maneira: depois que Scapinelli se afastava do espelho, pausava-se a câmera, e o cenário era preparado para a entrada do doppelgänger. A cena, então, era filmada duas vezes: na primeira, com Paul Wegener de um lado, na segunda, do outro.

Essa duplicidade da natureza humana já havia sido experimentada anteriormente no cinema. O outro, cujo roteiro fora escrito pelo teatrólogo Paul Lindau e que contara com a participação do célebre ator de teatro da época, Albert Bassermann, foi o primeiro dos filmes de autor, estreando no final de janeiro de 1913, meio ano antes de $O$ estudante de Praga. Assim como neste último, no filme $O$ outro, também existia um tipo de dilema do doppelgänger: um advogado, ao cair do cavalo, passa a transformarse ocasionalmente num criminoso, porém sem ter consciência do fato. No entanto, o motivo do doppelgänger restringe-se aqui a um caso clínico, a um mero distúrbio psicológico, que poderia ser igualmente representado no teatro, ao passo que, no filme de Ewers, assume o caráter místico e sobrenatural, que serve como um ótimo motivo temático para se explorarem as possibilidades técnicas do cinema. Como já dito anteriormente, Ewers escreveu um roteiro exclusivo para o filme, ou seja, um enredo pensado desde o início para o cinema, enquanto o roteiro de O outro, em contrapartida, fora escrito por Lindau segundo sua peça de teatro homônima. Enquanto Bassermann fazia mímica e, “como criminoso, torcia seu rosto em uma careta que pareceria hoje quase ridícula” (DIEDERICHS 1985: 29), Stellan Rye desenvolvia uma linguagem consideravelmente mais cinematográfica: intercalava tomadas em ambientes fechados com tomadas ao ar livre, trabalhava com os efeitos de luz e, com o stop trick, colocava dois Balduins idênticos em cena simultaneamente. Não surpreende, pois, o fato de ter sido o filme de Ewers aquele a conquistar o público e a crítica. Como afirmara George Lukács, em 1913, “no 'cinema' pode-se realizar tudo aquilo que os românticos esperaram, em vão, do teatro: uma movimentação maior e mais livre das personagens, a absoluta vivificação do fundo da cena, da natureza e dos interiores, das plantas e dos animais; uma vivificação que, no entanto, de maneira alguma se liga ao conteúdo e aos limites de uma vida comum” (LuKÁCs 1913: 1). Todo aquele mundo fantástico, místico e assustador do romantismo alemão ganhava vida na tela; transformava-se em imagem o que antes apenas a imaginação era capaz de visualizar.

O motivo temático central de $O$ estudante de Praga é a problemática da “dissociação do eu” (JÖRG 1994, p. 75), que, representada no filme pela perda do 
reflexo do espelho e, por conseguinte, da própria alma, é característica do romantismo. “A paranóia do ator de, no papel de um outro igual, ser seu próprio par funde-se em $O$ estudante de Praga com a paranóia romântica de acreditar que, para a sobrevivência tanto de uma como da outra natureza do homem, a separação de ambas deve ser levada a cabo - um processo acompanhado de grande risco, pois a desintegração custa a alma e a reintegração, a vida” (BRENNICKE/HEMBUs 1983: 29). Balduin, assombrado por seu doppelgänger, que, apesar de independente, não deixa de ser uma parte, um estilhaço de sua personalidade, busca desesperadamente libertar-se desse outro eu, de modo que, desvairado, atira na aparição, o que resulta, conseqüentemente, num ferimento fatal a si próprio. A necessidade premente do amaldiçoado de tomar as rédeas do próprio destino, de recuperar a própria identidade é tamanha, que faz com que ele se volte e ataque o doppelgänger, ainda que isso signifique atacar a si próprio. Conforme escreve Holger JÖRG:

Este impulso (por fim autodestrutivo) para libertar-se de maneira violenta do sinistro e desagradável alterego pode ser considerado dentre os traços essenciais do motivo do doppelgänger. Igualmente constitutiva é a idéia - oriunda do âmbito da crença de muitos povos primitivos na magia do encanto da alma e, respectivamente, da imagem - de que todo ferimento infligido à imagem de uma pessoa deve atingir a ela própria; um motivo que, sobretudo na literatura de doppelgänger do século dezenove, estabeleceu-se definitivamente e, assim, provavelmente foi também incorporado ao enredo de $O$ estudante de Praga (JÖRG 1994: 84-85).

O caráter inexoravelmente destrutivo do elo que une o estudante a seu alterego deixa-se perceber pela progressiva mudança de comportamento das duas personagens ao longo do filme. No início do filme, quando Balduin, em posse do dinheiro de Scapinelli, passa a cortejar a condessa Margit - mesmo estando esta já noiva do barão de WaldisSchwarzenberg -, ele está confiante, satisfeito com a nova vida e a possibilidade de felicidade que antevê para si junto da amada. As primeiras aparições do doppelgänger são então, de acordo com a distinção proposta por Holger JöRG, de “caráter passivoadvertivo” (JöRG 1994: 80): o alterego não age nem dirige a palavra a Balduin; é como se aparecesse apenas para lembrá-lo do acordo, do pacto irrevogável que os une. Ao mesmo tempo, porém, o doppelgänger surge sempre nos momentos em que Balduin está com a condessa - na sacada do castelo do conde, quando os dois começam a se aproximar; no cemitério, impedindo o primeiro beijo do casal -, de modo que, 
conquanto não haja de sua parte ação propriamente dita, ele frustra toda e qualquer iniciativa do herói em conquistar o objeto de seu desejo.

À medida que Margit passa a corresponder aos sentimentos de Balduin e os dois desenvolvem laços cada vez mais fortes, as aparições de seu alterego tornam-se mais e mais agressivas, adquirindo o que JöRG chama de “caráter ativo-ameaçador” (JörG 1994: 80): o doppelgänger, no lugar de Balduin, mata em duelo o barão de WaldisSchwarzenberg, com quem Balduin, a pedido do pai de Margit, prometera não duelar; senta-se à mesa de jogo com o estudante e desafia-o a jogar pela própria vida; e, por fim, persegue o herói pelas ruas de Praga até o culminante confronto no seu quarto, onde Balduin atira na aparição, matando a si próprio. Vê-se, assim, que o objetivo primeiro do acordo de Scapinelli era já a ruína e a morte do jovem. A possibilidade de felicidade que o dinheiro do acordo proporciona a Balduin traz consigo funestas conseqüências: quanto mais ele se aproxima de seus objetivos, mais se aproxima de sua própria destruição.

Antes, e mesmo depois do acordo com Scapinelli, o jovem estudante de Praga era um solitário, um homem para quem o amor se mostra intangível. Isso aparece representado na interessante figura de Lyduschka, a moça pobre e apaixonada que segue Balduin feito uma sombra, aonde quer que ele vá. Até aproximadamente a metade do filme, a figura jovem e “felina” da moça acompanha os infortúnios e fracassos do estudante, buscando diversas vezes conquistá-lo, a fim de salvá-lo do destino fatal que o aguarda. Entretanto, Balduin reiteradamente despreza seu amor, o que faz com que ela, por fim, passe a fazer intrigas junto à condessa Margit, a fim de envenená-la contra o estudante. De acordo com a sagaz análise de Otto RANK, Balduin “é impedido pelo seu próprio eu corpóreo de amar uma mulher, e assim como seu reflexo do espelho o segue qual um amante, assim Lyduschka segue a condessa como uma sombra, e ambos os doppelgänger colocam-se entre o par de heróis a fim de separá-los” (RANK 1914: 100).

Igualmente digna de nota é a misteriosa figura do senhor Scapinelli, com suas habilidades mágicas e sua manifesta charlatanice. A astúcia e persuasão de que se serve para convencer o ingênuo Balduin a assinar o contrato, bem como a data em que este se dá, dia 13 de maio de 1820 (sendo o número treze, na crença popular, definitivamente agourento), reforçam a idéia de tratar-se de um pacto com o diabo. Todavia, é equivocada a idéia de considerar Scapinelli como sendo o próprio diabo, ou mesmo uma entidade demoníaca, apenas pelo fato de ele possuir poderes mágicos e usá-los com fins malignos. Ele é antes o que dizem os letreiros: um velho aventureiro dotado de poderes 
mágicos. Em outras palavras, ele representa as pessoas com habilidades sobrenaturais, que são figuras típicas das lendas populares. Como diz PetzoldT, "bruxas, especialistas em magia, pactuantes com o diabo, maçons (...) são, segundo a superstição popular, possuidores de forças sobrenaturais que os capacitam para a magia branca ou negra” (PETzoldT 1978: 351). A constituição franzina, o jeito servil, a cartola, os óculos - sua figura é antes ridícula e caricaturesca do que sombria e ameaçadora. Ela não dispõe das características típicas que a caracterizem como uma entidade demoníaca: Scapinelli não traz, por exemplo, a “pena de galo” (JöRG 1994: 94), marca que identifica o diabo no Fausto de Goethe e que também aparece como símbolo do mal nos filmes mudos Nosferatu (1922) e Fausto (1926), de F.W. Murnau.

Em comparação com o reflexo de Balduin, este ser sem vontade própria cujo único propósito é perseguir e atormentar o estudante - seu eu original, o eu que nele inexiste -, Scapinelli aparece relativamente pouco no filme. Sua participação se dá mais no início do enredo, até o momento da libertação do reflexo, pois, a partir de então, o foco da ação se volta predominantemente para a relação entre Balduin e o doppelgänger; a figura de Scapinelli fica em segundo plano, cedendo o lugar a sua criação.

Não obstante, sua participação no curso dos acontecimentos é fundamental para o desdobramento da tragédia. Tomemos como exemplo o afogamento da condessa, ocasião em que ela e Balduin se conhecem e a partir da qual todo o enredo se desenvolve. Poder-se-ia ventilar aí a possibilidade do envolvimento de Scapinelli. Na cena em que Margit passa cavalgando pelos dois, ela perde o controle do cavalo justamente no momento em que estava ao lado esquerdo de Scapinelli - de acordo com a superstição popular, o lado mau. Contudo, como diz JöRG,

Não fica claro se 'o velho aventureiro', além do papel de observador atento, forjou, de maneira mágica, o acidente da filha do conde e seu subseqüente resgate por Balduin; nem, portanto, até que ponto ele, na sua função de aparente figura secundária, transforma-se no verdadeiro e invisível condutor dos eventos e, por conseguinte, em figura dominante (JÖRG 1994: 95).

Ele poderia igualmente ter apenas aproveitado o ensejo e o sentimento que percebe nos olhos de Balduin pela condessa para atraí-lo e convencê-lo a fazer o pacto. Interessante notar que o mesmo não se dá na segunda versão do filme, dirigida por Henrik Galeen, em 1926 (ironicamente, exatos treze anos depois). Neste segundo filme mudo, o diretor optou por dar maior destaque à figura de Scapinelli, mostrando 
claramente como este, com seus poderes mágicos, dirige o curso dos acontecimentos que levam à perdição de Balduin.

\section{Conclusões}

Buscamos mostrar a fase transitória do cinema como novo medium em direção a sua inserção e aceitação na vida cultural, exemplificadas pelo filme $O$ estudante de Praga como sendo a primeira produção de ambições declaradamente artísticas. A partir deste e outros exemplos pode-se perceber certo padrão no surgimento histórico dos media. Num primeiro momento, compara-se o novo medium com o antigo, este estabelecido e consolidado. Basta lembrarmo-nos da conhecida rejeição de Platão à escrita, julgando-a como influência negativa sobre a capacidade de memorização; também de denominações como foto-grafia ou cinemato-grafia, que se baseiam na escritura como patamar padrão; ou ainda da já tão gasta profecia do fim da "galáxia de Gutenberg” frente à digitalização. O mesmo se dá com relação à recepção inicial do cinema, visto primeiramente como uma ameaça à literatura e ao teatro. Numa segunda fase, objetiva-se integrar as características então elaboradas deste novo medium em teorias mais abrangentes. Pensamos aqui nas reflexões de Balázs ou Eisenstein, focalizando não mais aspectos comparativos, mas antes as propriedades da nova forma medial, sua singularidade e especificidade estética. Numa fase posterior, processam-se então as mudanças históricas mediais num contexto amplo, dentro de teorias sociais de cunho universal. Podemos citar aqui nomes como Walter Benjamin, Theodor W. Adorno, Umberto Eco, Jürgen Habermas ou Niklas Luhmann. Todos eles reservaram um determinado espaço de sua obra para destacar a relevância medial.

No tocante ao Estudante de Praga, vale lembrar que o sociólogo Siegfried KraCAUER o incluiu no seu livro de 1947, De Caligari a Hitler. O autor apresenta aqui uma argumentação que mais parece o resultado de um tour de force histórico da época do Pós-Guerra que busca construir os precursores do horror nazista, do que uma análise coerente. Sua tese parte da convicção de que o medium filme funcionaria como o sismógrafo psicológico de uma sociedade, transportando medos, neuroses, sentimentos e ideologias. “Os filmes de uma nação refletem de forma mais direta seu estado histórico do que outros media artísticos” (KRACAUER 1988: 53), pois nunca são produtos de um único indivíduo e dirigem-se a uma massa anônima. Ele vê, portanto, 
em muitos filmes da época, representações de uma dominação tirânica e, por conseguinte, uma disposição do povo alemão de se submeter a esta. Para apoiar esta análise, Kracauer se baseia em películas como Dr. Mabuse (1922), de Fritz Lang, Nosferatu (1922), de F.W. Murnau, O estudante de Praga (1913), de Rye/Ewers, O outro (1913), de Max Macks, e sobretudo o Caligari. Todavia, para sua análise sobre o sentimento das massas, escolheu, ironicamente, não os sucessos comerciais de grande apelo popular - entre os quais se encontrava um grande número de comédias, filmes de aventura e de entretenimento -, mas sim os Autorenfilme, os filmes de autor, que atingiram um público reduzido (talvez com exceção do Caligari), enquanto a "massa” do público alemão da época preferiu os mesmos filmes populares que os americanos ou ingleses. Parece-nos muito mais apropriado destacar a herança romântica como referência central do filme, e, neste contexto, o doppelgänger como elemento central da narrativa e configuração a ser explorada pelas possibilidades técnicas do filme. Parecido com Caligari, a configuração básica vem do “(...) doppelgänger, an offspring of a gothic tale, a late descendent of those split personalities of nineteenth-century Romantic literature who are haunted by their shadows and alter egos, form dangerous alliances with magic forces, create artificial beings who eventually escape their control, and usually end in self-destruction”. Balduin apresenta certo parentesco com "Cagliostro and Faust, Frankenstein and William Wilson, Dr. Jekyll and Mr. Hyde, and Dorian Gray” (Scheunemann 2003, p. 130). Assim, O estudante de Praga trouxe uma novidade ao cenário fílmico alemão: a de unir à tradição artística consolidada e respeitada do romantismo as possibilidades técnicas do novo medium, resultando, assim, numa produção referencial para a história do cinema.

\section{Referências bibliográficas:}

BAlÁzs, Béla. Der sichtbare Mensch. In: Diederichs, Helmut H. (org.). Béla Balázs, Schriften zum Film. Berlin, Henschel, 1962, v. 1.

BrenNiCKe, Ilona/HemBus, Joe. Klassiker des deutschen Stummfilms (1910 bis 1930). München, Goldmann, 1983.

Diederichs, Helmut. Der Student von Prag. Stuttgart, FOCUS-Verlagsgemeinschaft, 1985.

EWERS, Hanns Heinz. Der Kientopp. In: Morgen nr. 1, 11.10.1907, Berlin. 
EwERS, Hanns Heinz. Die Programmfrage. In: Erste Internationale Film-Zeitung, nr. 11, 18.3.1911, Berlin.

Ewers, Hanns Heinz. Antwort an Hans Kyser. In: B.Z. am Mittag. Nr. 44, 21.2.1913a, Berlin.

EWERS, Hanns Heinz. Der Film und ich. In: Lichtbild-Bühne, nr. 23, 7.6.1913b, Berlin.

JöRG, Holger. Die sagen- und märchenhafte Leinwand: Erzählstoffe, Motive und narrative Strukturen der Volksprosa im „klassischen“ deutschen Stummfilm (1910-1930). Sinzheim, Pro-Universitate-Verl., 1994.

KAEs, Anton (Hrsg.). Kino-Debatte. Texte zum Verhältnis von Literatur und Film 19091929. München, Deutscher Taschenbuch Verlag; Tübingen, Niemeyer, 1978.

Kinematograph. Der Kinematograph in der Medizin. Nr. 2, 1907, s.p., Berlin.

Korfmann, Michael. Rideamus in Brasilien: Ein nicht ganz so heiteres Leben. In: TÓPICOS 4/2002-1/2003, p. 40-41.

Kracauer, Siegfried. De Caligari a Hitler. Rio de Janeiro, Zahar, 1988.

KURTZ, Rudolf. Die Geschichte des Filmmanuskripts. In: Kinematograph, nr. 60, 1934, Berlin.

MENGIS, Carl. „Doppelgänger“; Stichwort in: BÄCHTOLD-STÄUBLI, Hanns/HofFMANNKRAYER, Eduard (Hrsg.). Handwörterbuch des deutschen Aberglaubens (9 Bde.). Berlin und Leipzig, de Gruyter, 1927-1942 (Repr. Berlin und New York: de Gruyter 1987), Band 2, 1927, p. 346-349.

Lotmann, Jurij M. Probleme der Kinoästhetik. Einführung in die Semiotik des Films. Frankfurt/M., Suhrkamp, 1977.

LUKÁCS, George. Gedanken zu einer Ästhetik des Kinos. In: Frankfurter Zeitung, Nr. 251, 10.09.1913, p. 1.

PAECH, Joachim. Literatur und Film. Stuttgart, Metzler, 1988.

PETZOLDT, Leander (Hg). Deutsche Volkssagen. München, Beck, 1978.

PrinZLER, Hans Helmut (Hg). DIF-Verleihkatalog Nr. 1. Hrsg. Vom Deutschen Institut für Filmkunde und von der Stiftung Dte. Kinemathek unter der Redaktion von $H$. H. Prinzler. Frankfurt, Wiesbaden und Berlin, Ludwig Vogt, 1986.

RANK, Otto. Der Doppelgänger. In: Imago. Zeitschrift für Anwendung der Psychoanalyse auf die Geisteswissenschaften, 3. Band, 1914, p. 97-164.

RoBinson, David. History of World Cinema. New York, Stein \& Day, 1973.

Scheunemann, Dietrich. Expressionist Films. Rochester, Camden House, 2003. 
SchoBert, Walter. Der Deutsche Avant-Garde Film der 20er Jahre. München, GoetheInstitut, 1989.

Tannenbaum, Herbert. Probleme des Kinodramas. In: Bild und Film (M.Gladbach), Nr. 3/4, 1913/14, p. 60.

ToEPLiTz, Jerzy. Geschichte des Films. Berlin, Henschelverlag, 1972, v. 1.

ZANDER, Peter. Thomas Mann im Kino. Berlin, Bertz und Fischer, 2005. 